\title{
Theoretical Study and Case Analysis for a Pre-dried Pyrolysis Coupled Lignite-Fired Power System
}

\section{Liu, Rongtanga ; Liu, Ming ${ }^{a^{*}}$; Yan, Junjie ${ }^{a}$}

aState Key Laboratory of Multiphase Flow in Power Engineering,Xi' an Jiaotong University, Xi' an 71 0049, China

*E-mail of the corresponding author: ming.liu@mail.xjtu.edu.cn

\begin{abstract}
Lignite, a kind of low rank coal, has the characteristics of high moisture, high volatile, high ash and low heat value. The low-temperature pyrolysis technology is potential to improve the utilization efficiency of lignite. Therefore, a lignite-based energy system integrated with pre-drying and lowtemperature pyrolysis was proposed in this paper. To assess the influence of pre-drying process, theoretical models were developed based on thermodynamics, and a case analysis was then performed to get the quantitative effect of pre-drying on efficiency of energy utilization. Results show that pre-drying on PPPS theoretical model can significantly improve the utilization of lignite by $1.46 \%$.
\end{abstract}

Keywords: Lignite; Pre-drying; Low-temperature pyrolysis; Energy efficiency; Case analysis. 


\section{Introduction}

Lignite is worldwidely considered as inferior fuel with abundant supply ${ }^{[1]}$ It is mainly used in power plants. However, the conventional lignite-fired power system (CLPS) is costly, not efficient and with high pollutant emissions. Lignite upgrading technologies, including pre-drying and pyrolysis, are effectively to improve lignite utilization efficiency. Therefore, many researches were conducted for the lignite pre-drying ${ }^{[2,3,4]}$ and pyrolysis ${ }^{[5,6]}$ technologies. However, these two technologies are isolatedly used. The integration of the lignite pre-drying and pyrolysis may realize the energy cascade utilization and then increase the utilization of lignite. Therefore, a pre-dried pyrolysis coupled lignite-fired power system (PPPS) was proposed in this paper.

The proposal of PPPS aims to overcome the disadvantages of the pyrolysis process by the integration of pre-drying. However, the research on influences of pre-drying process on pyrolysis system is not deepgoing and unambiguous. In this paper, theoretical models were developed based on thermodynamics, and a case analysis was then performed to get the quantitative effects of pre-drying. Moreover, the energy and exergy analysis were carried out to uncover the energy saving mechanism.

\section{System proposal}

The schematic of a PPPS is schematically presented in Fig.1 Raw lignite (point 1) is fed into the steam dryer and pre-dried primarily. The primary pre-dried lignite (point 2) is then fed into the drying unit and pre-dried ultimately. Afterwards, the ultimate pre-dried lignite (point 3 ) is led to the pyrolysis unit, heated by the elevated temperature flue gas, pyrolyzed and separated into char (point 4), tar (point 13), pyrolysis gas (point 21) and water (point 12) in pyrolysis furnace. The tar and pyrolysis gas are recycled as products. Nevertheless, the char is converted by a series of energy forms and transformed into electricity (point 20), eventually. Waste steams (point 5, 6, and 12) generated in the process are exhausted to environments. The heat source of pyrolysis furnace is the elevated temperature flue gas (point 11) extracted from the boiler unit and led to the inlet of the burner. The heat source of the drying unit in the pyrolysis system is the flue gas (point 10) exhausted from the pyrolysis chamber. The flue gas (point 9) is extracted to the boiler unit by the pump after releasing heat in the drying unit, the waste heat of which is recycled by the regenerative air preheaters. The heat source of the steam pre-drying unit is the $5 \#$ low-pressure extraction steam (point 7) from the turbine unit. The steam is led to the steam dryer, condensed after releasing heat, and recovered in the de-aerator. The steam dryer makes full use of the low grade energy contained by the extraction steam from regenerative system, and reduces the heat load in the pyrolysis system. 


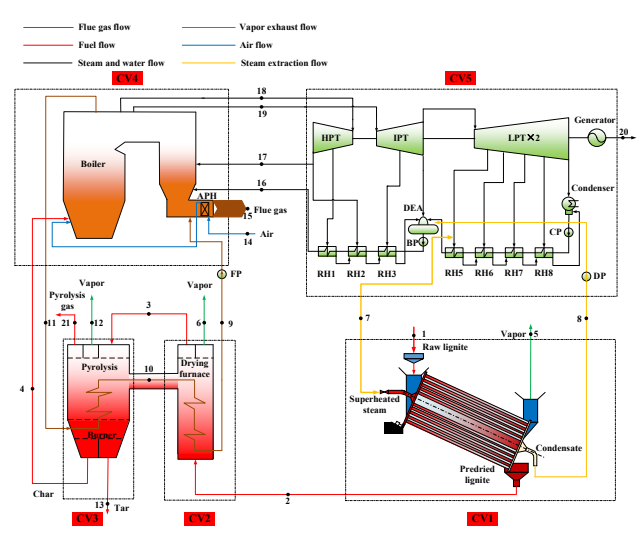

Fig.1 The pre-dried pyrolysis coupled lignite-fired power system. Note: APH, air preheater; HPT, high-pressure turbine; IPT, intermediate-pressure turbine; LPT, low-pressure turbine; DEA, deaerator; $\mathrm{RH}$, regenerative heater; $\mathrm{CP}$, condensate pump; BP, boiler feed-water pump exchangers; DP, drain water pump; FP, flue gas backflow pump; CV1, steam pre-drying unit; CV2, drying furnace unit; CV3, pyrolysis unit; CV4, boiler unit; CV5, steam turbine unit.

\section{Model development}

In this paper, the reference pressure and the temperature are given, as follows;

$$
\begin{aligned}
& p_{0}=0.1013 \mathrm{MPa} \\
& T_{0}=298.15 \mathrm{~K}
\end{aligned}
$$

The calculations of enthalpy, higher heating value, and exergy are all based on this condition. In this part, the belt pyrolysis furnace is selected as pyrolysis model. The following pyrolysis reaction occurs when the temperature and pressure of the pyrolysis furnace remains constant.

$$
\text { predried lignite }(\mathrm{s}) \rightarrow \operatorname{char}(\mathrm{s})+\operatorname{tar}(\mathrm{l})+\mathrm{gas}(\mathrm{g})+\text { water }(\mathrm{g})
$$

The parameters in pyrolysis process are shown in Table 1 , where $\mathrm{HHV}_{*}$ is higher heating value; $h_{*}$ is the specific enthalpy at $\mathrm{kJ}^{\circ} \mathrm{kg}^{-1} ; \mathrm{t}_{*}$ is the temperature at ${ }^{\circ} \mathrm{C} ; \lambda_{*}$ is pyrolysis production rate defined as the $(*)$ mass rate produced from unit mass of feed for pyrolysis furnace, $\mathrm{kg} \cdot \mathrm{kg}^{-1} \cdot \mu(\gamma)$ is the degree of pre-drying defined as the moisture mass released from unit mass of raw lignite (primary predried lignite), $\mathrm{kg} \cdot \mathrm{kg}^{-1}$. 
Table 1. The parameters of pyrolysis process.

\begin{tabular}{ccccc}
\hline Predried lignite & Char & Tar & Gas & Water \\
\hline$P_{0}$ & $P_{0}$ & $P_{0}$ & $P_{0}$ & $P_{0}$ \\
$h_{\mathrm{ul}}$ & $h_{\mathrm{c}}$ & $h_{\mathrm{t}}$ & $h_{\mathrm{g}}$ & $h_{\mathrm{wa}}$ \\
$\mathrm{HHV}$ & $\mathrm{HHV}_{\mathrm{c}}$ & $\mathrm{HHV}_{\mathrm{t}}$ & $\mathrm{HHV}_{\mathrm{g}}$ & - \\
$t_{\mathrm{ul}}$ & $t_{\mathrm{p}}$ & $t_{\mathrm{p}}$ & $t_{\mathrm{p}}$ & $t_{\mathrm{p}}$ \\
$\square-$ & $\lambda_{\mathrm{c}}$ & $\lambda_{\mathrm{t}}$ & $\lambda_{\mathrm{g}}$ & $\lambda_{\mathrm{wa}}$ \\
$B(1-\mu)(1-\gamma)$ & $\lambda_{\mathrm{c}} \cdot B(1-\mu)(1-\gamma)$ & $\lambda_{\mathrm{t}} \cdot B(1-\mu)(1-\gamma)$ & $\lambda_{\mathrm{g}} \cdot B(1-\mu)(1-\gamma)$ & $\lambda_{\mathrm{wa}} \cdot B(1-\mu)(1-\gamma)$ \\
\hline
\end{tabular}

By applying an enthalpy balance for the overall pyrolysis, the flue gas mass flow $\left(\mathrm{D}_{\mathrm{f}}^{\prime}\right)$ needed in the pyrolysis can be obtained:

$D_{\mathrm{f}}^{\prime}=\frac{\lambda_{\mathrm{c}}\left(\mathrm{HHV}_{\mathrm{c}}+h_{\mathrm{c}}\right)+\lambda_{\mathrm{t}}\left(\mathrm{HHV}_{\mathrm{t}}+h_{\mathrm{t}}\right)+\lambda_{\mathrm{g}}\left(\mathrm{HHV}_{\mathrm{g}}+h_{\mathrm{g}}\right)+\lambda_{\text {wa }} h_{\mathrm{wa}}-\left(\mathrm{HHV}_{\mathrm{ul}}+h_{\mathrm{ul}}\right)}{\left(h_{\text {pin }}-h_{\text {fin }}\right) \cdot \eta_{\mathrm{p}}}$

$\cdot B(1-\mu)(1-\gamma)$

where $\eta_{\mathrm{p}}$ is the thermal utilization efficiency of the pyrolysis furnace; and $h_{\text {pin }}$ is the specific enthalpy of flue gas in pyrolysis furnace inlet. Pyrolysis gases products are obtained as mixture, containing $\mathrm{CO}, \mathrm{H}_{2}, \mathrm{CO}_{2}$ and hydrocarbons $\left(\mathrm{CH}_{4}, \mathrm{C}_{2} \mathrm{H}_{4}, \mathrm{C}_{2} \mathrm{H}_{6}, \mathrm{C}_{3} \mathrm{H}_{6}\right.$ and $\left.\mathrm{C}_{3} \mathrm{H}_{8}\right)$. The $\mathrm{HHV}_{\mathrm{g}}$ is calculated as follow;

$$
\mathrm{HHV}_{\mathrm{g}}=\sum w_{\mathrm{i}} \cdot \mathrm{HHV}_{\mathrm{i}}
$$

where $\mathrm{HHV}_{\mathrm{i}}$ is the higher heating value of constituent (i) in pyrolysis gas calculated by CoolProp and $w_{\mathrm{i}}$ is the mass fraction of constituent (i). $D_{\mathrm{f}}$ and $D_{\mathrm{f}}^{\prime}$ are equal by adjusting $t_{\text {fin }}$ in MATLAB. $D_{\mathrm{f}}$ is the flue gas mass flow needed in the drying furnace unit. The energy and exergy flow ratios of each control volume and the power system to the input energy or exergy are defined as follows;

$$
\begin{aligned}
& \varepsilon_{\mathrm{L}}^{\mathrm{en}}=\frac{Q}{B \cdot \mathrm{LHV}_{\text {raw }}} \times 100 \% \\
& \varepsilon_{\mathrm{H}}^{\mathrm{en}}=\frac{Q}{B \cdot \mathrm{HHV}_{\text {raw }}} \times 100 \% \\
& \varepsilon^{\mathrm{ex}}=\frac{E}{B \cdot \mathrm{HHV}_{\text {raw }}} \times 100 \%
\end{aligned}
$$

where LHV is the lower heating value at $\mathrm{kJ} \cdot \mathrm{kg}^{-1} ; Q$ is the energy flow based on LHV in equation (6) and based on $\mathrm{HHV}$ in equation (7) at $\mathrm{kW} ; E$ is the exergy flow at $\mathrm{kW}$; and $\varepsilon$ is the efficiency. 


\section{Results and discussion}

\subsection{Results of calculation}

\subsubsection{Reference case}

The lignite pyrolysis power system (LPPS, only involving CV2, CV3, CV4 and CV5 in Fig.1) is derived from a conventional lignite-fired power system (CLPS ${ }^{[7]}$ with the pyrolysis system integrated, the parameters of which are set with reference to the CLPS. The parameters of live steam and reheat steam, including temperature, pressure and mass flow rate of LPPS are assumed similar to those of the CLPS. The temperature of boiler flue gas before the air preheater is assumed to be the same as the CLPS. The boiler exhaust temperature decreases to $126^{\circ} \mathrm{C}$ in the LPPS. The performances of the LPPS are calculated, and the thermodynamic properties of the state points of the LPPS are shown in Table 2.

Table 2. Thermodynamic properties of the state points of LPPS.

\begin{tabular}{clccccc}
\hline Point & Substance & $\begin{array}{c}\text { Temperature } \\
{ }^{\mathbf{C}}\end{array}$ & $\begin{array}{c}\text { Pressure } \\
\text { MPa }\end{array}$ & $\begin{array}{l}\text { Mass } \\
\text { rate,kg· } \mathbf{s}^{-1}\end{array}$ & $\begin{array}{c}\text { Exergy } \\
\mathbf{k J} \cdot \mathbf{k g}^{-1}\end{array}$ & $\begin{array}{l}\text { Exergy } \\
\text { flow,kW }\end{array}$ \\
\hline 2 & Raw lignite & 25 & 0.1013 & 187.9878 & 13080 & 2458900 \\
3 & Predried lignite & 300 & 0.1013 & 122.9542 & 20111 & 2472700 \\
4 & Char & 550 & 0.1013 & 84.7154 & 23913 & 2025800 \\
6 & Steam & 200 & 0.1013 & 65.0336 & 520.16 & 33828 \\
9 & Flue gas & 350 & 0.1013 & 526.1187 & 119.11 & 62665 \\
10 & Flue gas & 752.2 & 0.1013 & 526.1187 & 409.53 & 215460 \\
11 & Flue gas & 1200 & 0.1013 & 526.1187 & 823.43 & 433220 \\
12 & Steam & 550 & 0.1013 & 8.6068 & 927.96 & 7986.8 \\
13 & Tar & 550 & 0.1013 & 6.4797 & 34652 & 224530 \\
14 & Air & 25 & 0.1013 & 799.1080 & 0 & 0 \\
15 & Flue gas & 126 & 0.1013 & 863.3152 & 18.178 & 15693 \\
16 & Water & 284 & 30.400 & 527.7806 & 348.08 & 183710 \\
17 & Steam & 323.3 & 4.8310 & 448.2778 & 810.70 & 363420 \\
18 & Steam & 566 & 24.200 & 527.7806 & 1533.3 & 809260 \\
19 & Steam & 566 & 4.3480 & 448.2778 & 1125.3 & 504460 \\
20 & Electricity & - & - & - & - & 600000 \\
21 & Pyrolysis gas & 550 & 0.1013 & 19.8079 & 17956 & 355670 \\
\hline
\end{tabular}

By calculation, the thermal efficiency of the LPPS is $52.886 \%$ based on LHV, and $47.997 \%$ based on HHV. The exergy efficiency of the LPPS is approximately $48.00 \%$. 


\subsubsection{Pre-dried pyrolysis coupled lignite-fired power system}

The PPPS is put forward in previous part as shown in Fig.1.The parameters are assumed similar to those of the LPPS. The performances of the PPPS are calculated, and the thermodynamic properties of the state points are shown in Table 3.

Table 3. Thermodynamic properties of the state points of PPPS.

\begin{tabular}{clccccc}
\hline Point & Substance & $\begin{array}{c}\text { Temperature } \\
{ }^{\circ} \mathbf{C}\end{array}$ & $\begin{array}{c}\text { Pressure } \\
\text { MPa }\end{array}$ & $\begin{array}{c}\text { Mass flow } \\
\text { rate,kg·s }{ }^{-1}\end{array}$ & $\begin{array}{c}\text { Exergy } \\
\mathbf{k J} \cdot \mathbf{k g}^{-1}\end{array}$ & $\begin{array}{c}\text { Exergy } \\
\text { flow,kW }\end{array}$ \\
\hline 1 & Raw lignite & 25 & 0.1013 & 168.4627 & 13080 & 2203492 \\
2 & Predried lignite & 99.6 & 0.1013 & 126.6086 & 17417 & 2205200 \\
3 & Predried lignite & 300 & 0.1013 & 110.1837 & 20111 & 2215900 \\
4 & Char & 550 & 0.1013 & 75.9166 & 23913 & 1815400 \\
5 & Steam & 99.6 & 0.1013 & 41.8541 & 485.45 & 20318 \\
6 & Steam & 200 & 0.1013 & 16.4249 & 545.46 & 8959.2 \\
7 & Steam & 258.1 & 0.4232 & 53.4036 & 783.17 & 41824 \\
8 & Water & 145.7 & 0.4232 & 53.4036 & 82.178 & 4388.6 \\
9 & Flue gas & 420.96 & 0.1013 & 356.1046 & 162.25 & 57778 \\
10 & Flue gas & 600 & 0.1013 & 356.1046 & 287.78 & 102480 \\
11 & Flue gas & 1200 & 0.1013 & 356.1046 & 823.44 & 293230 \\
12 & Steam & 550 & 0.1013 & 7.7129 & 927.96 & 7157.3 \\
13 & Tar & 550 & 0.1013 & 5.8067 & 34652 & 201210 \\
14 & Air & 25 & 0.1013 & 716.1097 & 0 & 0 \\
15 & Flue gas & 126 & 0.1013 & 773.6530 & 18.177 & 14063 \\
16 & Water & 284 & 30.400 & 527.7806 & 348.08 & 183710 \\
17 & Steam & 323.3 & 4.8310 & 448.2778 & 810.70 & 363420 \\
18 & Steam & 566 & 24.200 & 527.7806 & 1533.3 & 809260 \\
19 & Steam & 566 & 4.3480 & 448.2778 & 1125.3 & 504460 \\
20 & Electricity & - & - & - & - & 569870 \\
21 & Pyrolysis gas & 550 & 0.1013 & 17.7506 & 17956 & 318730 \\
\hline
\end{tabular}

By calculation, the thermal efficiency of the PPPS is $54.507 \%$ based on LHV, and $49.458 \%$ based on HHV. The exergy efficiency of the PPPS is approximately $49.46 \%$. Obviously, due to the steam pre-drying process, the PPPS theoretical model can evidently increase the efficiency of the LPPS by approximately $1.46 \%$ based on the HHV, and by $1.62 \%$ based on the LHV at the calculation condition. 


\subsection{Energy and exergy analysis}

\subsubsection{Energy analysis}

The energy flows and losses of the LPPS and PPPS are illustrated in Fig.2a and Fig.2b respectively. The energy input to the system is expressed by the HHV of raw lignite in order to avoid the phenomenon of "Non-conservation of energy"[8]. The energy outputs involve $14.46 \%$ in the pyrolysis gas, $9.13 \%$ in the tar and $24.40 \%$ in electricity. The highest amount of energy loss is from the turbine unit, followed by the drying furnace in the LPPS. $29.63 \%$ energy is extracted from the boiler unit and only $56.83 \%$ energy is transferred to the steam. Comparatively, the electricity output in the PPPS is improved by $1.46 \%$. However, the pyrolysis gas and tar outputs are invariable because of the constant yield for the pyrolysis unit. Only $22.38 \%$ energy is extracted from the boiler unit and $63.42 \%$ energy is transferred to the steam. Using the energy analysis, the reason for the improved efficiency of the PPPS can be explained. The energy mostly discharged from the turbine is recycled by pre-drying lignite, and this energy is mainly transferred to the available energy in lignite.

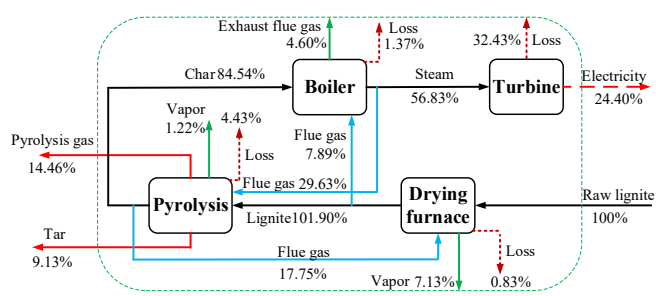

(a)

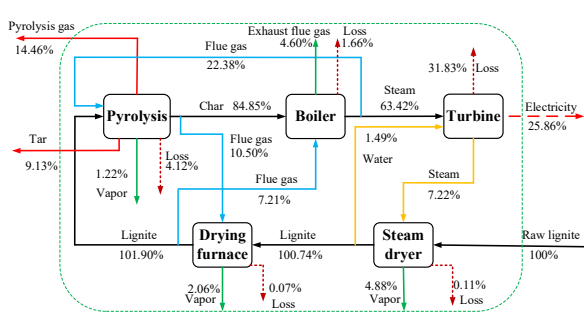

(b)

Fig.2 Energy flow and loss charts:(a)LPPS and (b) PPPS.

\subsubsection{Exergy analysis}

On the basis of the Table 2 and Table 3, the exergy flow, loss and destruction charts between the units of the LPPS and PPPS are illustrated in Fig. 3a and Fig. 3b, the data of which represent the exergy ratio to the input exergy of the system. The maximal loss and destruction in LPPS are the combustion process in the boiler unit, followed by the drying furnace unit. The low grade steam is firstly used to pre-dry the lignite, and then, the flue gas at the low temperature is used as the pre-drying heat source. In the whole drying process, the heat transfer temperature difference of PPPS is much lower than that of LPPS. Therefore, the exergy lost during the pre-drying is decreased significantly. Meanwhile, the lesser exergy extracting from the boiler also decreases the exergy lost in the boiler unit. Because of the exergy extracting, the lost in turbine is increased slightly. The exergy analysis suggests that the low heat transfer temperature difference and low grade energy recycling make the exergy efficiency increased. 


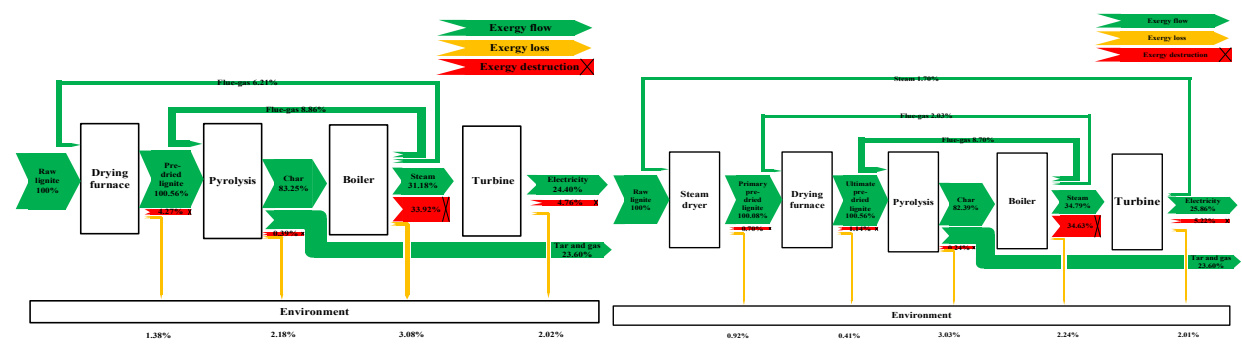

(a)

(b)

Fig.3 Exergy flow, loss and destruction charts:(a)LPPS and (b) PPPS.

\section{Conclusions}

A novel lignite-based energy system integrated with PPPS was proposed and thermodynamically analyzed in this paper. The thermal efficiency of the power system could be significantly increased by $1.62 \%(1.46 \%)$ based on the LHV (HHV). The energy mostly discharged from the turbine is recycled by pre-drying lignite, and this energy is mainly transferred to the available energy in lignite. The exergy analysis suggests that the low heat transfer temperature difference and low grade energy recycling make the exergy efficiency increased.

\section{References}

[1] Thielemann, T.; Schmidt, S.; Peter Gerling, J. Lignite and hard coal: Energy suppliers for world needs until the year 2100-An outlook. International Journal of Coal Geology 2007, 72(1), 1-14.

[2] Karthikeyan, M. Minimization of moisture readsorption in dried coal samples. Drying Technology 2008, 26(7), 948-955.

[3] Liu, M.; Yan, J.; Wang, J.; Chong, D.; Liu, J. Thermodynamic analysis on a lignitefired power system integrated with a steam dryer: Investigation on energy supply system of the dryer. Drying Technology 2015, 33(12), 1510-1521.

[4] Liu, M.; Wang, J.; Yan, J.; Chong, D.; Liu, J. A combined-type fluid-bed dryer suitable for integration within a lignite-fired power plant: System design and thermodynamic analysis. Drying Technology 2014, 32(8), 902-909.

[5] Yi, Q.; Feng,J.; Lu, B.; Deng, J.; Yu, C.; Li, W. Energy evaluation for lignite pyrolysis by solid heat carrier coupled with gasification. Energy\& Fuels 2013, 27(8) 4523-4533.

[6] Zhang, Y.; Wang, Y.; Cai, L.; Yao, C.; Gao, S.; Li, C.; Xu, G. Dual bed pyrolysis gasification of coal: Process analysis and pilot test. Fuel 2013, 112, 624-634.

[7] Liu, M.; Yan, J.; Bai, B.; Chong, D.; Guo, X.; Xiao, F. Theoretical study and case analysis for a predried lignite-fired power system. Drying Technology 2011, 29(10), 1219-1229.

[8] Liu, M.; Li, G.; Han, X.; Qin, Y.; Zhai, M.; Yan, J. Energy and exergy analyses of a lignite-fired power plant integrated with a steam dryer at rated and partial loads. Drying Technology 2017, 35(2), 203-217. 